FAYOUM UNIVERSITY MEDICAL JOURNAL

\title{
The dilemma of humanities in Medical Education
}

Mostafa, RM*. And Shafei, $A^{* *}$.

*Benha University , College of Medicine ,Egypt

${ }^{* *}$ Armed Forces College of Medicine, Egypt

Corresponding author :

Prof Randa M.Mostafa

Integrated Medical Program Manager,

College of Medicine,

Benha University

Email:

Mostafaranda@gmail.com

Randa.Moustafa@fmed.ac.edu.eg

Cellul. :002 01026266125

Fax :00233475139 
More than hundreds years ago, Oliver Wendell homes concluded in his book, the professor at the breakfast table (1883):

" The longer I live, the more I am satisfied of two things . First, that the truest lives are those that are cut rose-diamond fashion, with many facets. Second, that society in one way or another is always trying to grind us down to a single flat surface" (Mostafa and Mirghani, 2016)

This quotation shows perfectly well that our patients are not an object with single or multiple symptoms or diseases. They are human being, complex individuals with complex and complicated feelings, reactions, ideas and anxieties .

The general Medical Council (GMC 1993) stated that modern medical education needed radical reform, radical rethinking and reconsideration, directed towards a more holistic physician, to the more "humane" doctor with a holistic understanding, an analyzing ability, deep insight and creative vision outlined and governed by ethical sensitivity and approach, to apply this evidence and skills to the individual patient (MacNaughton, 2000). Humanism is considered to be an essential component of medical professionalism, one of a core competencies of physicians (Cohen and Sherif, 2014). Humanism and professionalism are essential abilities and skills to be inculcated in medical students alongside and parallel to the biomedical knowledge and clinical skills , their attainment is a long way to be travelled and affected by many factors. One of the most important factor is the process of education .

Professionalism and humanities education usually considered as :", a hidden curriculum" means that they are not operate within the actual formal curriculum but they are less officially outlined or recognized educational process which make them very difficult to teach but they have to be taught. This is exactly the great dilemma and challenge of teaching humanities in medical education .

Recently, Medical humanities and professionalism have been concentrated on specific ways of enhancing the experience of teaching and learning which consider in turn teacher's engagement. As a discipline, the medical humanities are perfectly aligned with the more progressive (literal and metaphorical) concept of life long learning as a journey or voyage of learning (Spicer et al., 2003).

The location of the elective role of hidden curriculum medical humanities content within the curricula is counterintuitive, given that the development of conceptual 
analytical and empathic qualities is held to be a universally required criterion for the doctor skilled in values- based medicine (Grant, 2002). Art, critical theory, history , law, literature, music, philosophy and theology fall under the mantle of medical humanities (Friedman, 2002). Through the previously mentioned electives, students can be taught the natural language of illness and suffering because it is the primary language of thought and feeling. This language explains why patient care is so frequently perceived as a journey with a clear narrative structure: the first consultation (chapter one of the story), and the history (flashback), through to the diagnosis (detection), therapeutic (journey towards resolution), and a satisfactory or unfortunate prognosis (the happy or sad ending).

By sharing this concept of the journey with patients, clinicians mirror image the nature and universal metaphor, that life itself is a journey on which each individual constructs and reconstructs their own narrative (Spicer et al., 2003). The more medical students listen to and understand how patients construct their narratives, the better they will understand how to alleviate the distress presented (Engel et al., 2008).

In conclusion, we would like to stress here that incorporating the medical humanities and professionalism in to the curriculum is an urgent need and could be achieved through different electives but on the same time, requires good teaching skills. It does not necessarily require a specific training. Having said that, it is our experience that medical teachers interested in the humanities can benefit from and also can enjoy such a great experience.

\section{Reference List}

Cohen, L.G. and Sherif,Y.A. (2014). Twelve tips on teaching and learning humanism in medical .education. Med. Teach. 36, 680-684

Engel,J.D., Zarconi,J., Pethtel,L.L., and Missimi S.A. (2008). Narrative in health care. New .(York, Radcliffe Publishing

Friedman,L.D. (2002). The precarious position of the medical humanities in the medical .school curriculum. Acad. Med. 77, 320-322

.Grant, V.J. (2002). Making room for medical humanities. Med. Humanit. 28, 45-48

MacNaughton,J. (2000). The humanities in medical education: context, outcomes and .structures. Med. Humanit. 26, 23-30 
Mostafa,R.M. and Mirghani,Z. (2016). Understanding caring through arts and medicine elective course, university of sharjah, College of Medicine approach. International .education and research Journal 2, 51-54

Spicer,J., Harrison,D., and Wining.J. (2003). The humanities in medical education. In Oxford .textbook of Medical education, K.Walsh, ed. Oxford), pp. 232-243 